\title{
Formulation development and evaluation of voriconazole sustained release tablets
}

\author{
*Manivannan Rangasamy, Venkata Krishna Reddy Palnati, Lakshmi Narayana Rao Bandaru \\ Department of Pharmaceutics, JKKMMRF'S - Annai JKK Sampoorani Ammal College of Pharmacy, Ethirmedu, B.Komarapalayam, \\ Namakkal Dt - 638183, Tamilnadu, India
}

\begin{abstract}
The present study involves in the formulation and evaluation of sustained release tablets of Voriconazole (250mg). The objective of the present study was to formulate Voriconazole sustained release tablets by wet granulation method by using natural (Xanthan gum, Karaya gum) and semi synthetic polymers (HPMC K100M). Lactose was used as diluting agent, Magnesium stearate was used as a lubricant and Talc was used as a glident. These sustained release tablets can release the drug up to 12 hours in predetermined rate. The formulated powder blend was evaluated for bulk density, tapped density, compressibility index and angle of repose. The formulated tablets were evaluated for physical characteristics of sustained release tablets such as thickness, hardness, friability, weight variation and drug content. The results of the formulations found to be within the limits specified in official books. The tablets were evaluated for In-vitro drug release studies by using USP type I dissolution test apparatus. The dissolution test was performed in $0.1 \mathrm{~N} \mathrm{HCL}$ for $2 \mathrm{hr}$ and phosphate buffer $\mathrm{pH} 6.8$ for 10hrs. The in-vitro cumulative drug release profile of all formulations F1-F10 at 12 hours showed $84.25 \%$ to $99.82 \%$ drug release, respectively. From the data it was clear that by increasing the amount of polymer in the formulation the amount of drug release was decreased. Hence, Formulation F9 was the most promising formulation as it gives satisfactory release $(99.82 \%)$ for 12 hours and F9 found to be the best formulation.
\end{abstract}

Key Words: Voriconazole, Xanthan gum, Karaya gum, HPMC K100M, Release Kinetics.

\section{INTRODUCTION}

Oral drug delivery has been the most widely utilized route of administration among the all routes because of certain advantages such as unit dosage form, low cost, cheapest for packaging etc. In the last two decades the drug delivery technology has developed rapidly and many novel oral drug delivery systems have been invented. Apart from these advantages this route suffers from certain drawbacks like patient noncompliance, multiple dosing and therapeutic failures. In order to overcome these drawbacks of conventional drug delivery there is a need for development of new drug delivery system or modified drug delivery system.

Sustained release system is a type of modified drug delivery system that can be used as an alternative to conventional drug delivery system. These systems sustain the release of drug and maintain the plasma drug concentration in therapeutic window except any fluctuation and increase the therapeutic efficacy of drug. They show their action by avoiding peak and trough in dosing and show constant plasma drug concentration in therapeutic window. Sustained release system have benefits like patient compliance, avoid multiple dosing, increase the plasma drug concentration, avoid side effects and overcome the problems associated with conventional system (Shalin et al., 2011).

Voriconazole is a triazole antifungal agent. The primary mode of action of Voriconazole is the inhibition of fungal cytochrome P-450-mediated 14 alpha-lanosterol demethylation, an essential step in fungal ergosterol biosynthesis.It has half-life about 1.7 hours and its oral

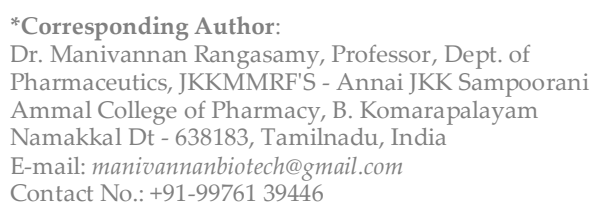

bioavailability is $96 \%$. To reduce the dosage frequency and related side effects Voriconazole can be given in the form of sustained release dosage form. This improves bioavailability of the drug, reduces frequency of dosing, thus minimizes side effects and enhances patient compliance. The present study outlines a systematic approach for the development of sustained release tablets of Voriconazole with a view to enhance its oral bioavailability and efficacy (Como and Dismukes, 1994).

\section{MATERIALS AND METHODS}

Voriconazole was received as a gift sample from Hetero drugs Ltd in Hyderabad. Xanthan gum, Karaya gum and HPMC K100M were purchased from Loba chemie, Mumbai. Lactose, Magnesium stearate was purchased from Thomos Baker Pvt Ltd., Mumbai.

\section{Formulation development}

Various batches of Voriconazole sustained release tablets were prepared by wet granulation technique. Tablets were prepared by adding PVP as a binder. All the ingredients were thoroughly mixed and granules are prepared by wet granulation technique. Then the granules are dried in a hot air oven. Finally granules are passed through sieve mesh \# 20 to get uniform size of granules. Previously dried granules were lubricated by adding magnesium stearate.

The above granules were compressed with the help of $8 \times 8 \mathrm{~mm}$ punch size, by keeping average weight $250 \mathrm{mg}$. After compression the tablets were evaluated for weight variation, hardness, thickness, friability, dissolution, and assay test were determined. The weights of the tablets were kept constant for formulations F1 to F10 was shown in table 1 (Kumar, 2010; Aulton, 2002; Mishra and Bansal, 2005). 
Table1: Composition of Voriconazole SR tablet.

\begin{tabular}{lcccccccccc}
\hline \multirow{2}{*}{ Ingredients } & \multicolumn{10}{c}{ Amount (mg/tablet) } \\
\cline { 2 - 12 } & F1 & F2 & F3 & F4 & F5 & F6 & F7 & F8 & F9 & F10 \\
\hline Voriconazole & 100 & 100 & 100 & 100 & 100 & 100 & 100 & 100 & 100 & 100 \\
Xanthan gum & 30 & 60 & - & - & - & - & 30 & 60 & - & - \\
Karaya gum & - & - & 30 & 60 & - & - & - & - & 30 & 60 \\
HPMC K100M & - & - & - & - & 30 & 60 & 30 & 30 & 30 & 30 \\
Lactose & 115 & 85 & 115 & 85 & 115 & 85 & 85 & 55 & 85 & 55 \\
Mg Streate & 2.5 & 2.5 & 2.5 & 2.5 & 2.5 & 2.5 & 2.5 & 2.5 & 2.5 & 2.5 \\
Talc & 2.5 & 2.5 & 2.5 & 2.5 & 2.5 & 2.5 & 2.5 & 2.5 & 2.5 & 2.5 \\
Total & 250 & 250 & 250 & 250 & 250 & 250 & 250 & 250 & 250 & 250 \\
\hline
\end{tabular}

\section{Physicochemical assay \\ Pre-compression parameters}

Loose Bulk Density (LBD)

An accurately weighed powder blend from each formula was lightly shaken to break any agglomerates formed and it was introduced in to a measuring cylinder. The volume occupied by the powder was measured which gave bulk volume. The loose bulk density (LBD) of powder blends was determined using the following formula:

Loose bulk density $=\frac{\text { Total weight of powder }}{\text { Total volume of powder }}$

\section{Tapped bulk density (TBD)}

An accurately weighed powder blend from each formula was lightly shaken to break any agglomerates formed and it was introduced into a measuring cylinder. The measuring cylinder was tapped until no further change in volume was noted which gave the tapped volume. The tapped bulk densities (TBD) of powder blends were determined using the following formula.

Tapped bulk density $=\frac{\text { Total weight of powder }}{\text { Total volume of tapped powder }}$

Carr's compressibility index

It is a simple index that can be determined on small quantities of powder. The compressibility indices of the formulation blends were determined using following Carr's compressibility index formula.

Carr's Compressibility Index $(\%)=\frac{\text { Tapped bulk density- bulk density }}{\text { Tapped bulkdensity }} \times 100$

\section{Angle of repose}

The angle of repose was determined by the funnel method. The accurately weighed powder was taken in a funnel. The height of the funnel was adjusted in such a way that the tip of the funnel just touched the apex of the heap of the powder. The powder was allowed to flow through the funnel freely onto the surface. The diameter of the powder cone was measured (Lachman, 1987). The angle of repose was calculated using the following equation.

$\theta=\tan ^{-1} \frac{h}{r}$

Where $\theta=$ angle of repose, $h=$ height, $\mathrm{r}=$ radius .

\section{Post-compression parameters}

\section{Shape of tablets}

The compressed tablets were examined under the magnifying lens for the shape of the tablet.

\section{Thickness}

Control of physical dimension of the tablets such as sizes and thickness is essential for consumer acceptance and to maintain tablet to tablet uniformity. The dimensional specifications were measured using screw gauge. The thickness of the tablet is mostly related to the tablet hardness can be uses as initial control parameter.

Hardness

There is a certain requirement of hardness in tablets so as to withstand the mechanical shocks during handling, manufacturing, packaging and shipping. For each formulation, the hardness of 6 tablets was determined using the Monsanto hardness tester. Monsanto hardness tester was used to measure hardness of the tablets. The whole experiment was performed in triplicate. It is expressed in $\mathrm{kg} / \mathrm{cm}^{2}$.

Friability

Friability is the measure of tablet strength. This test subjects a number of tablets to the combined effect of shock abrasion by utilizing a plastic chamber which revolves at a speed of $25 \mathrm{rpm}$ for 4 minutes, dropping the tablets to a distance of 6 inches in each revolution. A sample of pre-weighed tablets was placed in Roche friabilator which was then operated for 100 revolutions. The tablets were then dedusted and reweighed. Generally considered and acceptable limit is loss of less than $1 \%$ in weight. Percent friability ( $\%$ F) was calculated as:

$\%$ Friability $=\frac{\text { Initial weight }- \text { Final weight }}{\text { Initial weight }} \times 100$

\section{Weight variation}

The weight variation test is done by taking 20 tablets randomly and weighed accurately. The composite weight divided by 20 provides an average weight of tablet. Not more than two of the individual weight deviates from the average weight by $10 \%$ and none should deviate by more than twice that percentage. The average weight and standard deviation of the tablets were calculated (Kamlesh et al., 2001).

\section{Uniformity of Content}

The drug content in each formulation was determined by triturating 10 tablets and powder equivalent to $10 \mathrm{mg}$ was added in $100 \mathrm{ml}$ of $\mathrm{pH} 6.8$ phosphate buffer followed by stirring for 10 minutes. The solution was filtered through a $0.45 \mu \mathrm{m}$ membrane filter, diluted suitably and the absorbance of resultant solution was measured by using Shimadzu-1700 Pharmaspec UV-Visible spectrophotometer at 255nm using $\mathrm{pH} 6.8$ phosphate buffers (Shenoy, 2000).

\section{In-vitro drug release study}

The in-vitro release of Voriconazole from formulated tablets was carried out in acid buffer $\mathrm{pH} 1.2$ for 2 hours and then continued in phosphate buffer $\mathrm{pH} 6.8$ for 10 hours. The studies were performed in USP dissolution apparatus I, (Dissolution Test Apparatus, Model DS 8000, LAB INDIA Pvt Ltd) at $37 \pm 0.5^{\circ} \mathrm{C}$ and $100 \mathrm{rpm}$ speed. Samples were taken at hourly interval and analyzed for Voriconazole content at $255.0 \mathrm{~nm}$ by using UV-visible spectrophotometer (Model No. UV 3000+, Lab India Pvt Ltd.) (Higuchi, 2001; Mukesh, 2004).

\section{Stability studies}

The optimized formulation F9 packed in PVC blister pack then, they were stored at three different temperatures $4 \pm 2^{\circ} \mathrm{C}, 27 \pm 2^{\circ} \mathrm{C}$ and $45 \pm 2^{\circ} \mathrm{C}$ for 45 days at $\mathrm{RH} 75 \pm 5 \%$. At 15 days intervals, the tablets were evaluated for their physical appearance, drug content and drug excipients compatibility at specified intervals of time (table 8). 
Table 2: Calibration curve data of Voriconazole in $0.1 \mathrm{~N} \mathrm{HCl}$.

\begin{tabular}{ccc}
\hline Sl. No. & Concentration $(\mu \mathrm{g} / \mathbf{m L})$ & Absorbance \\
\hline 1 & 0 & 0 \\
2 & 5 & 0.114 \\
3 & 10 & 0.229 \\
4 & 15 & 0.334 \\
5 & 20 & 0.439 \\
6 & 25 & 0.544 \\
7 & 30 & 0.654 \\
\hline
\end{tabular}

Table 3: Calibration curve data of Voriconazole in phosphate buffer pH 6.8 .

\begin{tabular}{ccc}
\hline Sl. No. & Concentration $(\boldsymbol{\mu g} / \mathbf{m L})$ & Absorbance \\
\hline 1 & 0 & 0 \\
2 & 5 & 0.101 \\
3 & 10 & 0.19 \\
4 & 15 & 0.281 \\
5 & 20 & 0.369 \\
6 & 25 & 0.459 \\
7 & 30 & 0.556 \\
\hline
\end{tabular}

Table 4: Characteristics of Voriconazole SR tablet final blend.

\begin{tabular}{ccccc}
\hline $\begin{array}{c}\text { Formula- Bulk Density } \\
\text { tions }\end{array}$ & $\begin{array}{c}\text { Tapped } \\
(\mathrm{g} / \mathrm{ml})\end{array}$ & $\begin{array}{c}\text { Compressibi- } \\
\text { Density }^{*}(\mathrm{~g} / \mathrm{ml})\end{array}$ & $\begin{array}{c}\text { Angle of } \\
\text { lity Index }\end{array}$ (\%) \\
Repose $^{*}$
\end{tabular}

* - Number of measurements $=3$, results are expressed with \pm SD

Table 5: Physical properties of Voriconazole SR tablets.

\begin{tabular}{|c|c|c|c|c|c|}
\hline Formulations & $\begin{array}{c}\text { Thickness* } \\
\text { (mm) }\end{array}$ & $\begin{array}{c}\text { Hardness* } \\
\left(\mathrm{kg} / \mathrm{cm}^{2}\right)\end{array}$ & Friability* (\%) & $\begin{array}{c}\text { Weight } \\
\text { Uniformity* }(\mathrm{mg})\end{array}$ & $\begin{array}{c}\text { Content } \\
\text { uniformity* }(\%)\end{array}$ \\
\hline F1 & $3.48 \pm 0.14$ & $6.0 \pm 0.28$ & $0.85 \pm 0.29$ & Complies & $98.56 \pm 0.25$ \\
\hline F2 & $3.49 \pm 0.83$ & $6.2 \pm 0.62$ & $0.63 \pm 0.12$ & Complies & $97.35 \pm 0.92$ \\
\hline F3 & $3.49 \pm 0.67$ & $5.8 \pm 0.40$ & $0.53 \pm 0.10$ & Complies & $98.73 \pm 0.37$ \\
\hline $\mathrm{F} 4$ & $3.53 \pm 0.38$ & $6.1 \pm 0.97$ & $0.69 \pm 0.87$ & Complies & $99.46 \pm 0.59$ \\
\hline F5 & $3.49 \pm 0.14$ & $6.1 \pm 0.14$ & $0.67 \pm 0.19$ & Complies & $100.74 \pm 0.94$ \\
\hline F6 & $3.54 \pm 0.14$ & $5.7 \pm 0.95$ & $0.54 \pm 0.26$ & Complies & $98.57 \pm 0.54$ \\
\hline F7 & $3.54 \pm 0.21$ & $6.3 \pm 0.36$ & $0.51 \pm 0.66$ & Complies & $100.25 \pm 0.23$ \\
\hline F8 & $3.52 \pm 0.73$ & $5.7 \pm 0.32$ & $0.53 \pm 0.43$ & Complies & $98.22 \pm 0.40$ \\
\hline F9 & $3.46 \pm 0.20$ & $6.1 \pm 0.48$ & $0.72 \pm 0.19$ & Complies & $99.38 \pm 0.37$ \\
\hline F10 & $3.54 \pm 0.21$ & $6.3 \pm 0.36$ & $0.51 \pm 0.66$ & Complies & $100.25 \pm 0.23$ \\
\hline
\end{tabular}

* - Number of measurements $=3$, results are expressed with \pm SD

Table 6: In-vitro dissolution data of Voriconazole SR tablets.

\begin{tabular}{|c|c|c|c|c|c|c|c|c|c|c|}
\hline $\begin{array}{l}\text { Time } \\
\text { (Hrs) }\end{array}$ & F1 & F2 & F3 & F4 & F5 & F6 & F7 & F8 & F9 & F10 \\
\hline 0 & 0 & 0 & 0 & 0 & 0 & 0 & 0 & 0 & 0 & 0 \\
\hline 1 & 9.1 & 8.06 & 10.12 & 7.24 & 8.92 & 7.89 & 6.62 & 7.21 & 8.71 & 7.62 \\
\hline 2 & 19.01 & 20.02 & 17.96 & 14.36 & 18.63 & 15.96 & 13.25 & 16.96 & 17.02 & 15.11 \\
\hline 3 & 30.25 & 26.96 & 20.36 & 25.96 & 27.35 & 29.53 & 22.57 & 24.52 & 21.62 & 22.37 \\
\hline 4 & 38.6 & 37.01 & 33.65 & 39.01 & 36.25 & 34.52 & 30.25 & 31.45 & 32.25 & 30.47 \\
\hline 5 & 48.69 & 40.57 & 45.63 & 44.25 & 43.01 & 46.36 & 38.51 & 41.65 & 40.75 & 38.06 \\
\hline 6 & 59.25 & 51.31 & 54.96 & 56.56 & 53.65 & 55.26 & 47.37 & 46.52 & 49.13 & 45.25 \\
\hline 7 & 69.13 & 65.2 & 62.45 & 66.89 & 69.23 & 62.32 & 55.96 & 50.05 & 54.52 & 52.09 \\
\hline 8 & 78.52 & 74.25 & 73.65 & 70.36 & 77.63 & 71.36 & 60.05 & 57.7 & 63.25 & 59.92 \\
\hline 9 & 85.17 & 80.05 & 82.31 & 84.23 & 83.41 & 79.45 & 67.23 & 61.59 & 70.01 & 65.63 \\
\hline 10 & 91.83 & 89.31 & 90.89 & 89.25 & 91.25 & 87.91 & 71.57 & 69.81 & 77.91 & 71.82 \\
\hline 11 & - & 93.38 & - & 92.01 & - & 92.96 & 79.67 & 75.18 & 88.36 & 82.74 \\
\hline 12 & - & - & - & - & - & - & 89.56 & 84.25 & 99.82 & 93.69 \\
\hline
\end{tabular}


Table 7: Drug release kinetics of optimized batch (F9).

\begin{tabular}{ccccccc}
\hline $\begin{array}{c}\text { Time } \\
\text { (Hrs) }\end{array}$ & $\begin{array}{c}\text { Square } \\
\text { root of } \\
\text { time }\end{array}$ & $\begin{array}{c}\text { Log } \\
\text { time }\end{array}$ & $\begin{array}{c}\text { \% drug } \\
\text { release }\end{array}$ & $\begin{array}{c}\text { Log \% } \\
\text { drug } \\
\text { release }\end{array}$ & $\begin{array}{c}\text { \% drug } \\
\text { remain- } \\
\text { ing }\end{array}$ & $\begin{array}{c}\text { Log \% } \\
\text { drug } \\
\text { remaining }\end{array}$ \\
\hline 0 & 0 & - & 0 & - & 100 & 2 \\
1 & 1 & 0 & 8.71 & 0.94 & 91.29 & 1.96 \\
2 & 1.414 & 0.301 & 17.02 & 1.231 & 82.98 & 1.919 \\
3 & 1.732 & 0.477 & 21.62 & 1.335 & 78.38 & 1.894 \\
4 & 2 & 0.602 & 32.25 & 1.509 & 67.75 & 1.831 \\
5 & 2.236 & 0.699 & 40.75 & 1.61 & 59.25 & 1.773 \\
6 & 2.449 & 0.778 & 49.13 & 1.691 & 50.87 & 1.706 \\
7 & 2.646 & 0.845 & 54.52 & 1.737 & 45.48 & 1.658 \\
8 & 2.828 & 0.903 & 63.25 & 1.801 & 36.75 & 1.565 \\
9 & 3 & 0.954 & 70.01 & 1.845 & 29.99 & 1.477 \\
10 & 3.162 & 1 & 77.91 & 1.892 & 22.09 & 1.344 \\
11 & 3.317 & 1.041 & 88.36 & 1.946 & 11.64 & 1.066 \\
12 & 3.464 & 1.079 & 99.82 & 1.999 & 0.18 & 0.745 \\
\hline
\end{tabular}

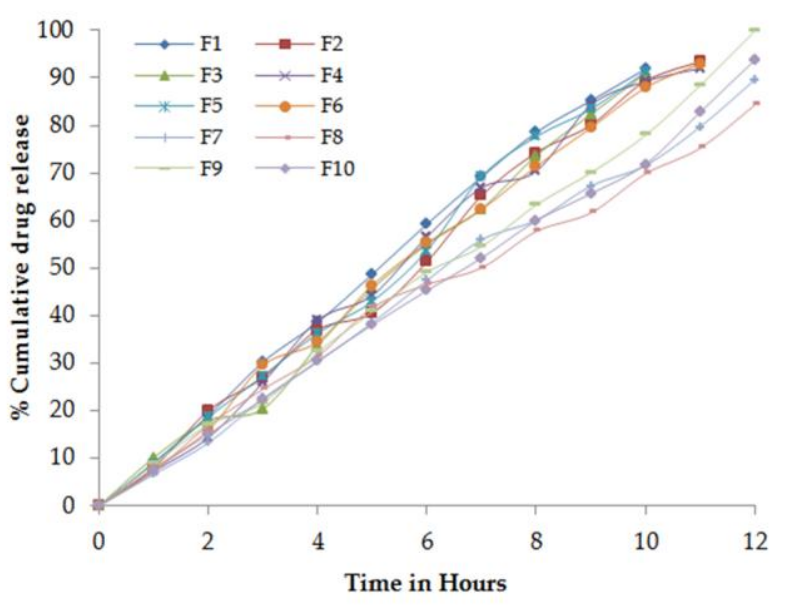

Figure 1: In vitro drug release profile for tablets of batches F1 to F10.

Table 8: Stability studies result of Voriconazole SR tablets.

\begin{tabular}{|c|c|c|c|}
\hline Parameters & $\begin{array}{l}\text { After } \\
15 \text { days }\end{array}$ & $\begin{array}{l}\text { After } 30 \\
\text { days }\end{array}$ & $\begin{array}{l}\text { After } 45 \\
\text { days }\end{array}$ \\
\hline Physical appearance & No change & No change & No change \\
\hline Weight variation (mg) & $249 \pm 3.34$ & $256 \pm 2.55$ & $255 \pm 4.23$ \\
\hline Thickness (mm) & $3.51 \pm 1.87$ & $3.53 \pm 2.86$ & $3.54 \pm 3.98$ \\
\hline Hardness $\left(\mathrm{kg} / \mathrm{cm}^{2}\right)$ & $6.4 \pm 0.23$ & $6.3 \pm 0.64$ & $6.2 \pm 0.99$ \\
\hline Friability (\%) & $0.51 \pm 0.05$ & $0.53 \pm 0.08$ & $0.53 \pm 0.06$ \\
\hline Drug content ( $\% /$ tablet $)$ & $100.34 \pm 0.34$ & $99.81 \pm 0.29$ & $99.01 \pm 0.87$ \\
\hline
\end{tabular}

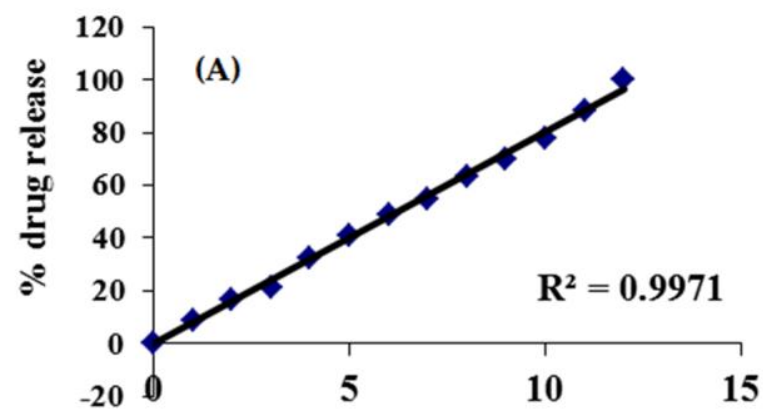

Time (hrs)

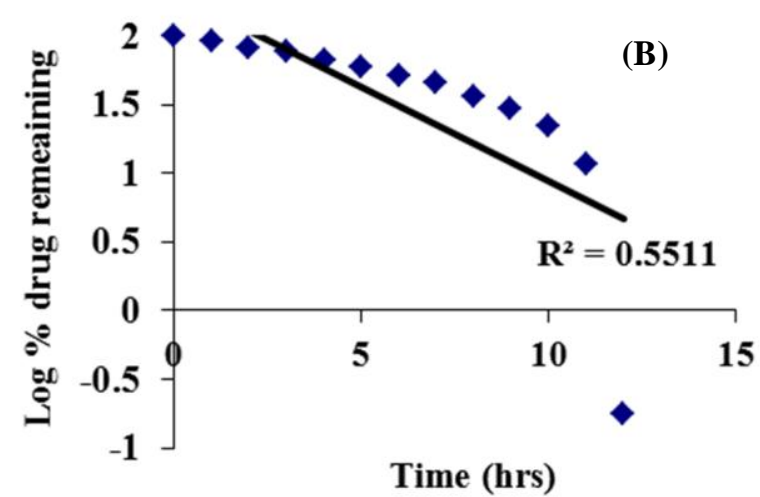

Time (hrs)
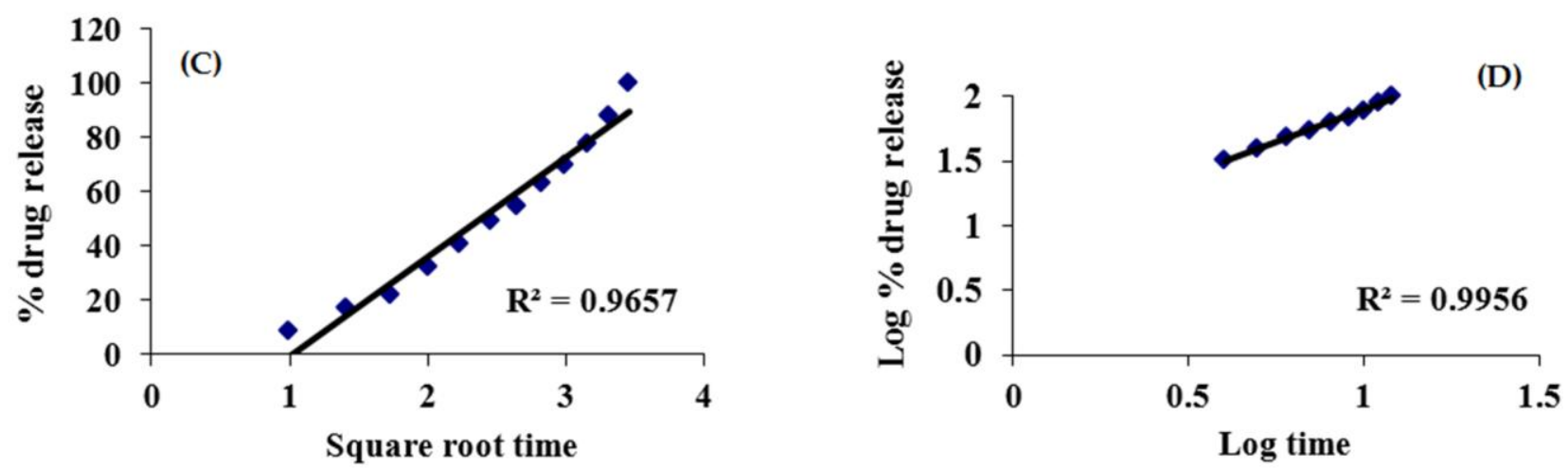

Figure 2: Kinetics plot of F9 (a) Zero Order, (b) First Order, (c) Higuchi's and (d) Peppas Koresmeyer's. 


\section{RESULTS AND DISCUSSION}

In the present study 10 formulations of Voriconazole matrix tablets with variable concentration of polymer were prepared and evaluated for Physicochemical, invitro drug release studies.

\section{Preformulation studies}

\section{Melting point determination}

Melting point of Voriconazole was found to be in the range $127-130^{\circ} \mathrm{C}$, which complied with IP standards, indicating purity of the drug sample.

\section{Solubility}

Voriconazole is low soluble in water. It is insoluble in chloroform, acetone, Methylene chloride and ether.

\section{Drug-polymers compatibility study}

Compatibility studies were performed using FT-IR spectrophotometer. The IR spectrum of pure drug and physical mixture of drug and polymer were studied. The characteristic absorption peaks of Voriconazole were obtained at $1473 \mathrm{~cm}^{-1}$ and $1028 \mathrm{~cm}^{-1}$. The peaks obtained in the spectra of each formulation correlates with the peaks of drug spectrum. This indicates that the drug was compatible with the formulation components.

\section{Standard calibration curve of Voriconazole}

Standard calibration curve of Voriconazole was determined by plotting absorbance vs. concentration at $255 \mathrm{~nm}$ in $0.1 \mathrm{HCl}$ and phosphate buffer $\mathrm{pH} 6.8$ and it follows the Beer's law. The results were show in table 2 and table 3. The regression values were $0.9991,0.999$ and slope values were $0.021,0.018$.

\section{Evaluation of sustained release tablet formulations Pre-compression parameters}

Voriconazole sustained release powder blend was evaluated for its pre-compression parameters like Bulk density, tapped density, Angle of repose and compressibility index and the results were given in table 4 .

\section{Post-compression parameters}

The post compression parameters like Shape, dimensions, Hardness, Friability, Weight variation, Drug content uniformity of the tablets were given in table 5 .

\section{In-vitro drug release studies}

All the formulated sustained release tablets of Voriconazole were subjected to in-vitro release studies using $0.1 \mathrm{~N}$ $\mathrm{HCl}(\mathrm{pH}$ 1.2) for first two hours and phosphate buffer $\mathrm{pH}$ 6.8 for remaining hours. The in-vitro drug release of all ten formulations of sustained release tablets was shown in table 6 and figure 1. The drug release data of optimized formulation was fitted into several kinetic models (figure 2) to know the mechanism of drug release.

\section{CONCLUSION}

Sustained release matrix tablets Voriconazole was formulated by wet granulation technique using the combination of natural polymers Xanthan gum, Karaya gum and semi synthetic polymer HPMC K100M. Infrared spectra of the drug along with polymers reveal that there is no significant interaction between drug and polymers.

Preformulation studies were done initially and the results were found within the limits. The evaluation tests results are found to be within Pharmacopial specifications. From in-vitro dissolution study it was concluded that the formulation F9 containing Karaya gum and HPMC K100M in the ratio 1:1 was taken optimized formulation of sustained release tablet for 12 hours release as it fulfills all the requirement of sustained release tablet.

Kinetic studies were observed as Case - II release mechanism of drug through polymeric membrane was found through diffusion and rate of diffusion is controlled by swelling of polymer. From the stability studies, it was concluded that no significant difference in the drug content between initial and formulations stored at $4 \pm 2{ }^{\circ} \mathrm{C}$, $27 \pm 2^{\circ} \mathrm{C}$ and $45 \pm 2^{\circ} \mathrm{Cfor} 45$ days at $\mathrm{RH} 75 \pm 5 \%$ for 45 days.

\section{REFERENCES}

Aulton, ME. (2002). Pharmaceutics-The science of dosage form design, 2nd ed., Churchill Livingstone, London. pp. 322-334.

Como, JA and Dismukes, WE. (1994). Overview of oral azole drugs as systemic anti-fungal therapy. N Engl J Med, Issue 4, Pages 263-272.

Higuchi, T. (2001). Mechanism of sustained action medication, theoretical analysis of rate of release of solid drugs dispensed in solid matrices. J. Pharm Sci, Volume 52, Issue 12, Pages 1145-1149.

Kamlesh, J., Rajendra, B. and Milind J. Umekar. (2011). Formulation of sustained release metformin hydrochloride matrix tablets: influence of hydrophilic polymers on the release rate and in vitro evaluation. International Journal of Research in Controlled Release, Volume 1, Issue 3, Pages 157-163.

Kumar G., Juyal, V. and Badoni, PP. (2010). Formulation and evaluation of matrix tablets of Acarbose. Drug Invention Today, Volume 2, Issue 5, Pages 264-267.

Lachman, L., Liberman, HA. and Nicholas, G. (1987). Sustained release dosage forms, 2nd Ed., Mumbai: Varghese publishing house. pp. 439 440.

Mishra, B. and Bansal, A. (2005). Development and in-vitro evaluation of hydrophilic matrix tablets of Diltiazem hydrochloride. Acta pharmaceutica. 47, Pages 115-126.

Mukesh, C. (2004). A more relevant dissolution method for evaluation of floating drug delivery system, Dissolution techniques.

Shalin A. Modi, Gaikwad, PD., Banker, VH., Pawar, SP. (2011). A review of sustained release drug delivery system. International Journal of Pharma Research and Development, Volume 2, Issue 12, Pages147-158.

Shenoy (2000). Hand book pharmaceutical chemicals. Multitech Publication. pp:204

Subrahmanyam, CVS. (2001). Textbook of Physical pharmaceutics. 2nd Ed., New delhi: Vallabh Prakashan. pp. 253-261. 